\title{
The Potential of Granisetron in Preventing Spinal Anesthesia Induced Hypotension on Non-Obstetric Procedure
}

\author{
Poppy Nuradi ${ }^{1}$, Made Subagiartha ${ }^{1}$, Putu Agus Surya Panji ${ }^{1}$, \\ Tjokorda GA Senapathi ${ }^{1}$ \\ ${ }^{1}$ Department of Anesthesiology and Intensive Care, Faculty of Medicine, Universitas Udayana/Sanglah General \\ Hospital, Bali, Indonesia \\ Corresponding Author: Poppy Nuradi
}

\begin{abstract}
Hypotension is a common adverse effect seen after spinal anesthesia. In recent literature the use of 5-HT3 receptor antagonists has been proposed to prevent spinal anesthesia induced hypotension (SAIH). We present the use of granisetron in several cases as prevention strategy for SAIH in our center. All 10 eligible subjects received $3 \mathrm{mg}$ granisetron diluted in 10 $\mathrm{cc}$ normal saline 5 minutes prior to spinal anesthesia, on patients who undergone nonobstetric procedure. Eight patients showed good response without evidence of hypotension, while the other two patients had hypotension managed well with ephedrine. As many as 9 patients had no bradycardia, while shivering was noted in 3 patients. All patients didn't suffer from nausea/vomiting, due to its effectiveness of granisetron acts as antiemetic agents. Granisetron, has great affinity specifically for 5HT3 receptor. It blocked the Bezold Jarisch Reflex (BJR) activation that will lead to hypotension and bradycardia. In a nutshell, granisetron has shown its potential as a prevention strategy for hypotension after spinal anesthesia in the majority of our cases above.
\end{abstract}

Keywords: Hypotension, Spinal anesthesia, granisetron, 5-HT3, BJR

\section{INTRODUCTION}

Hypotension is a frequent complication seen after spinal anesthesia. It affects $33 \%$ of the non-obstetric and 70$80 \%$ of the obstetric population.[1,2] The incidence varies depending on each patient's history, the anesthetic technique used, and comorbidities.[3] Although hypotension after spinal anesthesia can be managed using vasopressor and fluid administration, the presence of hypotension can lead to altered cardiovascular rhythm, nausea, and vomiting, altered consciousness, which increased the risk of aspiration. [2,4] Another sequela observed after spinal anesthesia together with hypotension is bradycardia.[5,6]

Severe neurological complication may arise due to hypotension and hypoperfusion, so-called anterior spinal artery syndrome (ASAS). Although some major surgery can induced direct hypotension or embolization to the anterior spinal artery branches, however, SAIH also contributed for this rare syndrome.[7-9]

The mechanism behind spinal anesthesia-induced hypotension (SAIH) is believed due to sympathetic blockade induce venous blood pooling in the lowermost regions, which affects $20 \%$ of total blood circulation, hence decrease systemic vascular resistance, preload, and cardiac output. The decrease in preload will stimulate the mechanoreceptor and chemoreceptor on the left ventricle wall, which is serotonin sensitive. $[5,10,11]$ Serotonin released by platelets, enterochromaffin cells, and the nervous system will bind to its receptor, specifically 
Poppy Nuradi et.al. The potential of granisetron in preventing spinal anesthesia induced hypotension on nonobstetric procedure.

5-HT3 type then activate the Bezold Jarisch Reflex (BJR). BJR is a cardioinhibitory mechanism with triad hypotension, bradycardia, and apnea. ${ }^{12}$ Stimulation of peripheral 5-HT3 receptor in the epicardium of the left ventricle will send its stimulation to the afferent vagal pathway to nucleus solitaries tract in the central nervous system, subsequently releasing more serotonin and increase its binding with the centrally located 5-HT3 receptor in the brain, which leads to vasodilatation, hypotension, and bradycardia.[13]

The most common agent used is ondansetron and granisetron meanwhile, granisetron has great specific affinity for 5HT3 receptor compared to ondansetron, which has affinity to other receptors. Only small studies and cases involving the nonobstetric population found in worldwide literature. The use of granisetron in Indonesia is still limited, moreover on its application to prevent hypotension, for this reason, we would like to present several cases of the use of granisetron to prevent hypotension after spinal anesthesia in our center.

\section{CASE HISTORY}

We present as many as 10 case studies conducted in our center. Preoperative measurement was crucial to determine the patient selections, all patients with contraindication for neuraxial block, hypersensitivity history to regional anesthetic or 5HT3 receptor antagonist, Body Mass Index more than $35 \mathrm{~kg} / \mathrm{m} 2$, cardiovascular comorbidities, patients receiving selective serotonin reuptake inhibitors or migraine medications, as well as the requirement for blood transfusion during procedure and dehydration were excluded from the study. Inclusion and exclusion criteria can be seen in table 1 . Crystalloid $10 \mathrm{~mL} / \mathrm{kg}$ for 15 minutes was given to all patients subsequently hydration status determined by measuring the inferior vena cava diameter using ultrasound. Dehydration is defined when after given preloading for over 15 minutes the IVC diameter is below $1.5 \mathrm{~cm}$.[14]

\begin{tabular}{|l|l|}
\hline \multicolumn{2}{|c|}{ Table 1. Inclusion and Exclusion criteria } \\
\hline Inclusion & Exclusion \\
\hline Lower abdominal elective surgery non-obstetric with spinal anesthesia technique & Patient didn't agree to participate \\
ASA status I-II & Cardiovascular problems \\
$20-60$ years old & SSRI or migraine drugs consumption \\
Height $146-174 \mathrm{~cm}$ & Dehydration \\
& Contraindicated for spinal anesthesia \\
& Allergy to the medication used \\
& BMI $>35 \mathrm{~kg} / \mathrm{m} 2$ \\
& Requiring blood transfusion \\
\hline
\end{tabular}

All subjects received $3 \mathrm{mg}$ granisetron diluted in $10 \mathrm{cc}$ normal saline 5 minutes prior to spinal anesthesia. Spinal anesthesia was using $27 \mathrm{G}$ Quincke spinal needle performed at L3-4 or L4-L5 level with lateral recumbent position. Hyperbaric bupivacaine $12,5 \mathrm{mg} 0,5 \%$ administered into subarachnoid space right after cerebrospinal fluid confirmation. The time to reach T5 or T6 level sensoric block and complete motoric block in all patients was achieved in less than 5 and 8 minutes, respectively.

Hemodynamic was measured before spinal anesthesia and at 3 minutes intervals up to 15 minutes after spinal anesthesia, followed by 15 minutes intervals until the end of procedure. The primary outcome was the incidence of hypotension, and the secondary outcome observed were bradycardia, nausea, vomiting, and shivering during surgery. Ephedrine $5 \mathrm{mg}$ IV was given if the patient experience decrease blood pressure below $90 / 60 \mathrm{mmHg}$ or $\geq 20 \%$ from baseline, or decrease mean arterial pressure (MAP) $<65 \mathrm{mmHg}$. The presence of bradycardia, heart rate $<50$ beats/minute, will be treated with 0.5 atropine IV. Any vomiting episode and shivering will be rescued with $10 \mathrm{mg}$ 
Poppy Nuradi et.al. The potential of granisetron in preventing spinal anesthesia induced hypotension on nonobstetric procedure.

metoclopramide IV, and $25 \mathrm{mg}$ pethidine IV, respectively.

\section{CASE 1}

A 25-year-old previously healthy female presented with tumor of left proximal tibia who undergone core biopsy with spinal anesthesia. Pre-operative measurement concluded with physical status ASA II. Six minutes after induction shivering was observed and was salvaged with pethidine. The patient's mean HR was 62 beats/minute, BP 108/76 mmHg during 45 minutes duration of operation. Neither hypotension, bradycardia nor nausea/ vomiting was observed.

\section{CASE 2}

A 42-year- old female, ASA II patient, was posted for double J-stent replacement. During 45 minutes of surgery, no significant hemodynamic alterations were found. Shivering and nausea/vomiting were also unnoticed.

\section{CASE 3, CASE 4}

Third case and fourth case, a 38 years old ASA II and a 34 years old ASA I, previously healthy males, who were scheduled for lithotripsy due to urinary tract stone. Neither of them experiences hypotension, bradycardia, shivering, or nausea/vomiting during 55 minutes and 75 minutes of surgery.

\section{CASE 5}

A 29-year-old ASA I, an athletic male with $5 \%$ burn injury on the right inferior limb was planned for debridement surgery. There were no episodes of hypotension, bradycardia, shivering or nausea/vomiting during 40 minutes of surgery.

\section{CASE 6}

A 40- year-old female presented with abnormal uterine bleeding due to suspicion of malignancy was scheduled for dilation and curettage for biopsy. Preoperative assessment concluded physical status ASA II. Fortunately, her hydration status after crystalloid preloading was normal, IVC diameter was approximately 2 $\mathrm{cm}$. Ten minutes after spinal anesthesia, the patient experienced shivering, which then rescued with pethidine, and at twelve minutes a drop of blood pressure was observed BP $86 / 59 \mathrm{mmHg}$ followed with bradycardia (49 times/minute) compared to her baseline BP and heart rate were 110/90 $\mathrm{mmHg}$ and 65 times/minute. Ephedrine and atropine were given to overcome hypotension and bradycardia. Hemodynamic measurement increased to 1minute interval until stabilized. In spite of the occurrence of hypotension, bradycardia and shivering, no other following episode or other sequelae was recorded.

\section{CASE 7}

A 33-year-old male, ASA II, was planned for inguinal hernia repair. Upon examination no signs of incarceration or perforation. The surgery was done in 90 minutes without complication, and there were no episodes of hypotension, bradycardia, shivering, nausea/vomiting were observed.

\section{CASE 8, CASE 9}

A 21 years old male, and A 23 years old female, underwent appendectomy surgery due to appendicitis were eligible to join the study. After all preoperative assessments both concluded with physical status ASA I. Both surgeries were done successfully for 50 minutes and 60 minutes, without evidence of hypotension, bradycardia, shivering, nausea/vomiting during surgery.

\section{CASE 10}

52 years old female, ASA II, otherwise healthy, was posted to have open reduction internal fixation surgery after a close fracture on the right fibula. After careful pre-operative evaluation, she met the criteria of this study. Nine minutes after induction hypotension was noted (88/53 $\mathrm{mmHg}$ ), and was rescued with ephedrine, 
Poppy Nuradi et.al. The potential of granisetron in preventing spinal anesthesia induced hypotension on nonobstetric procedure.

after close monitoring, her blood pressure was back to normal in less than 5 minutes. Shivering was experienced at 18 minutes. Up until the end of the surgery, no further episodes of hypotension, bradycardia, and shivering were observed. Nausea/vomiting wasn't seen during 120 minutes of surgery.

Summary of all 10 Cases in table 2.

\begin{tabular}{|c|c|c|c|c|c|c|c|c|c|}
\hline \multicolumn{10}{|c|}{ Tabel 2. Summary of all 10 Cases } \\
\hline No & Sex & Age & Procedure & ASA & Basal SBP (mmHg) & $\mathbf{H}$ & $\mathbf{B}$ & $\mathbf{N} / \mathbf{V}$ & $\mathbf{S}$ \\
\hline 1 & $\mathrm{~F}$ & 25 & Core Biopsy & II & 100 & - & - & - & + \\
\hline 2 & $\mathrm{~F}$ & 42 & Double J Stent Replacement & II & 140 & - & - & - & - \\
\hline 3 & $\mathrm{M}$ & 38 & Lithotripsy & II & 110 & - & - & - & - \\
\hline 4 & $\mathrm{M}$ & 34 & Lithotripsy & $\mathrm{I}$ & 120 & - & - & - & - \\
\hline 5 & $\mathrm{M}$ & 29 & Debridement & I & 120 & - & - & - & - \\
\hline 6 & $\mathrm{~F}$ & 41 & Abnormal Uterine Bleeding Dilatation and Curettage & II & 110 & + & + & - & + \\
\hline 7 & M & 33 & Inguinal hernia repair & II & 120 & - & - & - & - \\
\hline 8 & $\mathrm{M}$ & 21 & Appendectomy & I & 120 & - & - & - & - \\
\hline 9 & $\mathrm{~F}$ & 23 & Appendectomy & $\mathrm{I}$ & 120 & - & - & - & - \\
\hline 10 & $\mathrm{~F}$ & 52 & ORIF & II & 110 & + & - & - & + \\
\hline
\end{tabular}

\section{DISCUSSION}

On this presented cases 2 out of 10 cases $(20 \%)$ experienced hypotension, 1 case experienced bradycardia (10\%), while shivering was noted in 3 cases $(30 \%)$. The hypotension observed in cases above happened during the first 15 minutes, which in tune with prior study where hypotension after spinal anesthesia usually occurs during the first 15-30 minutes after induction.[15] We discovered one patient who experienced hypotension also experienced bradycardia, this can be explained through BJR mechanism. Activation of BJR resulting in both hypotension and bradycardia.

Despite using the same preventive regimen on all patients, spinal anesthesia induces hypotension couldn't be avoided in some patients. There are several risk factors for hypotension after spinal anesthesia on non-obstetric patients, low basal systolic blood pressure less than $120 \mathrm{mmHg}$, and age $\geq 40$ years old.[1] There are 3 cases with age more than 40 years old, 2 of them experienced hypotension, while 4 cases have low basal systolic blood pressure and 2 of them had hypotension.

BJR reflex can be enhanced after high spinal block, massive bleeding, and hypovolemia.[12] Only one patient with bleeding (case 6), although her hydration status was normal after crystalloid preloading, without any evidence of blood transfusion needed through pre-operative assessment, she experienced hypotension and bradycardia. The presence of such sequelae after spinal anesthesia in this patient could be caused by the history of bleeding, even though her prior spinal anesthesia examination didn't meet the exclusion criteria, which was massive bleeding in needing a blood transfusion or physical status beyond ASA II. The limitation of all these cases presented above was blood loss during surgery wasn't recorded, which might be the black hole for case 6 explanation.

The complication of hypotension and spinal anesthesia may rarely cause anterior spinal artery syndrome (ASAS), which results in severe neurologic deficit. ASAS occurs when occlusion or hypoperfusion occurs at the anterior spinal artery or any major radiculomedullary branches. The artery of Adamkiweicz, the great radicular artery which arises from aorta between T9-L2, is the most common location for occlusion.[8,9] Most common etiology is usually due to aortic surgery induced direct hypotension or embolization, however, spinal anesthesia induced vasospasm to a radicular feeding artery and/or perioperative hypotension is considered as the underlying cause of ASAS.[7-9] It leads to hypoperfusion in the anterior spinal artery and resulting in ischemia or even infarction to the spinal cord. Therefore hypotension must be prevented in patients undergoing spinal 
Poppy Nuradi et.al. The potential of granisetron in preventing spinal anesthesia induced hypotension on nonobstetric procedure.

anesthesia to avoid major complications such as ASAS.

The use of granisetron has shown its potential as a prevention strategy for hypotension after spinal anesthesia in the majority of our cases above. In total of 8 patients showed good response without evidence of hypotension, while the other two patients was managed well with ephedrine without any further episodes of hypotension. As many as 9 patients had no bradycardia, while shivering was noted in 3 patients. All patients didn't suffer from nausea/vomiting, due to its effectiveness of granisetron acts as antiemetic agents.

Several previous studies of granisetron used to prevent hypotension after spinal anesthesia was found, they mostly focused on obstetric patients due to the high incidence of hypotension in patient undergoing section caesarean. Though only limited study in non-obstetric population just like this presented article. Bommala et al, showed a significant reduction of hypotension and ephedrine use in granisetron group.[6] Shrestha et al, revealed granisetron is an effective agent to stabilize haemodynamic after spinal anesthesia induction.[10] In Indonesia, the use of Granisetron is still limited, moreover on its use as a preventive mechanism toward hypotension after spinal anesthesia, hence further experimental study is needed.

In a nutshell, the used of $3 \mathrm{mg}$ granisetron 5 minutes prior to spinal anesthesia induction as preventive approach of SIAH revealed a good result in majority of our cases, $80 \%$ didn't experience hypotension, $90 \%$ didn't suffer from bradycardia, only $30 \%$ had shivering, while $100 \%$ didn't complain any nausea or vomiting. Given all result from our 10 patients, provoke the need for further analytic study in our center, which results can be used to determine its significant effectivity.

\section{CONCLUSION}

Based on case series and discussion carried out, it can be concluded that blocked the Bezold Jarisch Reflex (BJR) activation that will lead to hypotension and bradycardia. In a nutshell, granisetron has shown its potential as a prevention strategy for hypotension after spinal anesthesia in the majority of our cases above.

\section{Conflict of interest}

The authors declare no conflict of interest, financial or otherwise.

\section{Acknowledgements: none.}

\section{Patients' Consent}

The patient has given permission and informed consent for the publication of this case report.

\section{REFERENCES}

1. Liu SS, Mcdonald SB. Current Issues in Spinal Anesthesia. Anesthesiology. 2001; 94(5): 888-906.

2. Gao L, Zheng G, Han J, Wang Y, Zheng J. Effects of prophylactic ondansetron on spinal anesthesia-induced hypotension: a meta-analysis. International Journal of Obstetric Anaesthesia. 2015;

3. Tubog TD, Kane TD, Pugh MA. Effects of Ondansetron on Attenuating Spinal Anesthesia-Induced Hypotension and Bradycardia in Obstetric and Nonobstetric Subjects: A Systematic Review and MetaAnalysis Effects of ondansetron on attenuating spinal anesthesia-induced hypotension and brady. American Association of Nurse Anesthetists. 2017; 85(2):113-22.

4. Heesen M, Klimek M, Rossaint R. Prevention of Spinal Anesthesia-Induced Hypotension During Cesarean Delivery by 5-Hydroxytryptamine-3 Receptor Antagonists: A Systematic Review and Meta-analysis and Meta-regression. 2016; 123(4):977-88.

5. Megahed MAB, Hady AMA, Sayed AEDM, Mohamed MA. Clinical Comparative Study of The Effects of Intravenous Ondansetron and Granisetron on Hemodynamic Changes, Shivering, And Motor \& Sensory Blockade Induced By Spinal Anesthesia In Women Undergoing Cesarean Section. New York Science Journal. 2017;10(6):7-16. 
Poppy Nuradi et.al. The potential of granisetron in preventing spinal anesthesia induced hypotension on nonobstetric procedure.

6. Bommala S, Mukkara M, Samantaray A, Pasupuleti H, Reddycogu DM, Pudotha SS, et al. Effects of Intravenous Ondansetron and Granisetron on Haemodynamic Changes during Spinal Anaesthesia in Nonobstetric Population: A Randomised Double-blind Study. Journal of Clinical and Diagnostic Research. 2019;13(5):UC01-4.

7. Gong J, Gao H, Gao Y, Yin W, Jin Y, Huang $Y$, et al. Anterior spinal artery syndrome after spinal anaesthesia for caesarean delivery with normal lumbar and thoracic magnetic resonance imaging. Journal of Obstetrics and Gynaecology. 2016;36(7):855-6.

8. Rahman M, Rahman S, Bakar Siddik A, D Hossain M, Musa J, Hamjah R, et al. A Review on the Pathophysiology and Management of Anterior Spinal Artery Syndrome. Journal of Spine Research and Surgery. 2020;02(04).

9. Zaphiratos V, McKeen DM, Macaulay B, George RB. Persistent paralysis after spinal anesthesia for cesarean delivery. Journal of Clinical Anesthesia [Internet]. 2015;27(1):68-72. Available from: http://dx.doi.org/10.1016/j.jclinane.2014.08. 003

10. Shrestha BK, Acharya SP, Marhatta MN. Use of Granisetron for prevention of hypotension and bradycardia due to spinal anesthesia: A double blind randomised control trial. Journal of Society of Anesthesiologists of Nepal. 2015;1(1):36-9.

11. Anisha, Narayan S. A comparative study between intravenous Ondansetron and Granisetron in attenuation of hypotension during spinal anaesthesia in patients undergoing caesarean section. Indian Journal of Clinical Anaesthesia. 2020;7(3): 470-6.

12. Campagna JA, Carter C. Clinical Relevance of the Bezold - Jarisch Reflex. Anesthesiology. 2003;98(5):1250-60.

13. Arya S, Belwal S, Uniyal B, Tiwari B, Sharma P. Bezold Jarisch Reflex- New Interest , Old Phenomenon. 2020;8(1):24-9.

14. Spivey M, West M. Ultrasound in Shock. In: Manual of Emergency and Critical Care Ultrasound. 2nd ed. United Kingdom: Cambridge; 2011. p. 258-61.

15. Holte K, Foss NB, Svensén C, Ph D, Lund $\mathrm{C}$, Madsen JL, et al. Intravascular Volume. Anesthesiology. 2004;100(22):281-6.

How to cite this article: Nuradi P, Subagiartha M, Panji PAS et.al. The potential of granisetron in preventing spinal anesthesia induced hypotension on non-obstetric procedure. International Journal of Research and Review. 2021; 8(10): 423-428. DOI: https://doi.org/10. 52403/ijrr.20211057 